Simbiosis Mutualisme Perpustakaan dengan Media Cetak sebagai Upaya Membudayakan Membaca dan Menulis bagi Masyrakat Muhammad Rohmadi

- Faktor Pengembangan dan Isu dalam Masalah Karier Pustakawan Masriyatun

Menguak Informasi via Alexa.com sebagai Evaluasi Menuju Optimalisasi

- Keberaksesan terhadap Perpustakaan dan Institusinya Wiji Suwarno

Profesionalisme Pustakawan dalam Layanan Informasi SriAnawati

Public Space dan Private Space: Posisi Strategis Perpustakaan dalam Mendukung

Pembelajaran Kolaboratif Purwani Istiana

Mewujudkan World-class Professionalism of Librarians di Era Library Mobile

Yuni Nurjanah

- Tantangan dan Kesiapan Pustakawan di Era Digital Dian Hapsari

Formulasi Strategi Membangun Eksistensi Perpustakaan Perguruan Tinggi

(Studi UPT Perpustakaan UNS Tahun 2015) RiahWiratningsih

Optimalisasi Perpustakaan Desa dalam Rangka Meningkatkan Pendidikan Masyarakat Bambang Hemanto

Optimalisasi Layanan Perpustakaan Perguruan Tinggi melalui Pemanfaatan Social

- Media Networking sebagai Media Komunikasi antara Perpustakaan dan Pemustaka Haryanto

Rekonstruksi Budaya Hukum Masyarakat dalam Pemulihan Pascakonflik Etnis Madura dan Melayu di Kabupaten Sambas 


\section{Jurnal \\ Pustaka Ilmiah \\ Jurnal Ilmiah UPT Perpustakaan UNS}

Jurnal Pustaka Ilmiah (JPI) sebagai media kreasi para pustakawan, guru, dosen, dan praktisi dalam pengembangan profesi secara berkelanjutan. Berbagai ide dan gagasan kreatif menjadi bahan kajian yang diimplementasikan dalam berbagai model pengembangan bahan pustaka, baik cetak maupun online. Kreativitas menjadi akar pengembangan ilmu pengetahuan sepanjang hayat dengan berbagai model pengembangan budaya literasi di perpustakaan. Keindahan dan kecermatan dalam sebuah tulisan ilmiah dan nonilmiah akan dapat direalisasikan secara nyata oleh sumber daya manusia untuk menghasilkan SDM yang unggul dan kreatif dengan membaca dan menulis untuk menyinari dunia. Budaya literasi menjadi upaya untuk pengembangan dan pemberdayaan perpustakaan sebagai pusat sumber belajar untuk mendukung tri dharma perguruan tinggi.

\section{SUSUNAN REDAKSI JURNAL PUSTAKA ILMIAH UPT PERPUSTAKAAN UNS}

Penanggung Jawab

Ketua Redaksi

Wakil Redaksi

Sekretaris

Penyunting Ahli
: Dr. Muhammad Rohmadi, M.Hum.

: Dra. Tri Hardiningtyas, M.Si.

: Haryanto, M.IP.

: Bambang Hermanto, S.Pd., M.IP., Henny Perwitosari, A.Md.

: 1. Dr. Muhammad Rohmadi, M.Hum. (Universitas Sebelas Maret);

2. Drs. Widodo, M.Soc.Sc. (Universitas Sebelas Maret);

3. Drs. Harmawan, M.Lib. (Universitas Sebelas Maret).

: Daryono, S.Sos., M.IP.; RiahWiratningsih, S.S., M.Si., Dinar Puspita Dewi, S.Sos., M.IP.; Sri Utari, S.E.

: Nurul H., A. Md.; Novi Tri Astuti, A.Md.

: Aji Hartono, A. Md.; Agus Sriyono, A.Md.; Aris Suprihadi, S.IP.

\section{DITERBITKAN OLEH UPT PERPUSTAKAAN UNS}

REDAKSI JURNAL PUSTAKA ILMIAH

Alamat: Jl. Ir. Sutami 36A Kentingan, Surakarta 57126

Telp./Fax.: (0271) 654311; email: jurnal.pustaka.ilmiah@gmail.com 


\section{PENGANTAR REDAKSI}

Salam pustaka. Dengan rasa syukur kepada allah swt. Segenap redaksi Jurnal Pustaka Ilmiah (JPI) mengucapkan banyak terima kasih kepada para penulis yang telah berkontribusi untuk penerbitan perdana JPI. Dengan terbitnya JPI ini berarti UPT Perpustakaan UNS telah memiliki media penulisan bagai para pustakawan, dosen, tenaga kependidikan, guru, dan praktisi untuk menuangkan ide dan gagasan kreatifnya secara tertulis.

Dalam penerbitan JPI perdana ini disajikan sepuluh tulisan antara lain: (1) Faktor Pengembangan dan Isu Dalam Masalah Karier Pustakawan (Masriyatun), (2) Menguak Informasi via Alexa.com sebagai Evaluasi Menuju Optimalisasi Keberaksesan terhadap Perpustakaan dan Institusinya (Wiji Suwarno), (3) Profesionalisme Pustakawan dalam Layanan Informasi (Sri Anawati), (4) Public Space dan Private Space: Posisi Strategis Perpustakaan dalam Mendukung Pembelajaran Kolaboratif (Purwani Istiana), (5) Mewujudkan World-class Professionalism of Librarians di Era Library Mobile (Yuni Nurjanah), (6) Tantangan dan Kesiapan Pustakawan di Era Digital (Dian Hapsari), (7) Formulasi Strategi Membangun Eksistensi Perpustakaan Perguruan Tinggi (Studi UPT Perpustakaan UNS Tahun 2015) (Riah Wiratningsih), (8) Optimalisasi Perpustakaan Desa dalam Rangka Meningkatkan Pendidikan Masyarakat (Bambang Hemanto), (9) Optimalisasi Layanan Perpustakaan Perguruan Tinggi melalui Pemanfaatan Social Media Networking sebagai Media Komunikasi antara Perpustakaan dan Pemustaka (Haryanto).

Akhirnya, redaksi JPI mengucapkan banyak terima kasih kepada Kepala UPT Perpustakaan UNS yang telah memberikan dukungan dan memfasilitasi untuk penerbitan JPI. Selain itu, ucapan terima kasih juga disampaikan kepada para penulis, tim redaksi, dan Yuma Pressindo, yang telah mempersiapkan dari awal sampai terbitnya JPI.

Desember 2015

Ketua Redaksi, 


\section{SAMBUTAN}

Dr. Muhammad Rohmadi, M.Hum.

Kepala UPT Perpustakaan UNS

\section{“Jadikalah tulisanmu sebagai cermin kehidupanmu di masa sekarang dan masa depan"}

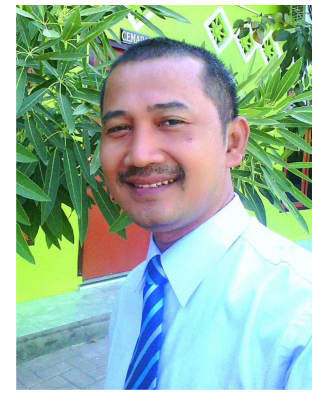

Selamat dan sukses atas diterbitkannya Jurnal Pustaka Ilmiah (selanjutnya disingkat JPI). Sambutan ini diberikan dalam rangka penerbitan perdana JPI. Jurnal ini sebagai media kreativitas dan pengembangan softskill para pustakawan, guru, dosen, dan praktisi untuk menuangkan ide dan gagasan dalam berbagai konteks kehidupan. Berbagai isu terkait dengan pengembangan perpustakan, pusat sumber belajar, pendidikan, dan budaya literasi akan menjadi topik-topik yang disajikan dalama jurnal ilmiah ini.

Diterbitkannya JPI sebagai bukti kepedulian UPT perpustakaan Ilmiah dalam rangka turut berpartisipasi untuk mengembangkan dan membudayakan literasi untuk para pustakawan dan civitas akademika di UNS dan luar UNS. Berbagai model pengembangan softskill menjadi alaternatif untuk membekali dan memperkuat jaringan kerja sama penulisan antarkelembagaan. Dengan demikian, kerja sama antarpustakawan dan pemustaka dapat diwujudkan dengan berbagai model dalam bidang literasi.

Penerbitan JPI sebagai upaya untuk memotivasi semua pustakawan menulis, baik ilmiah maupun nonilmiah. Para pustakawan harus menjadi pionir dalam bidang penulisan. Hal ini sebagai bentuk kepedulian dan keteladaan para pustakawan yang memproses, menyajikan, dan menikmati bahanbahan pustaka cetak dan noncetak di perpustakaan. Ketersedian bahan pustaka akan menjadi bahan paling nyata untuk dikembangkan dalam berbagai model perwujudan teknik peniulisan. Hal terpenting yang harus dimiliki oleh para pustakawan adalah semangat untuk berbagai pengetahuan melalui tulisan.

Kepedulian setiap sumber daya manusia kepada kelembagaan dapat dituangkan dalam berbagai model pengabdian, salah satunya adalah melalui tulisan. Berbagai ide dan gagasan dapat direalisasikan dengan berbagai model bentuk artikel jurnal, buku, modul, monograf, dan lain sebagainya. Para civitas akademika, guru, praktisi harus memiliki keterampilan menulis sebagai bentuk perwujudan pengembangan diri secara berkelanjutan. Berbagai tulisan dan referensi sudah disajikan tetapi masih sangat minim untuk diimplementasikan dalam kehidupan. Banyak orang pandai dalam berbicara tetapi masih sedikit yang menuangkan ide dan gagasannya dalam bentuk tulisan.

Akhirnya, keluarga besarUPT Perpustakaan UNS mengucapkan banyak terima kasih kepada Rektor, Wakil Rektor, pengelola JPI, penulis, dan semua pihak yang telah mendukung penerbitan perdana JPI. Semoga dengan diterbitkannya JPI ini dapat menjadi media untuk menulis para pustakawan, dosen, guru, dan praktisi dalam bidang iptek dan seni. Ucapan terima kasih juga diucapkan kepada percetakan Yuma Pressindo yang telah membantu mempersiapkan dari awal sampai terbitnya JPI ini. Akhirnya, semoga JPI dapat memberikan nilai kemaslahatan untuk umat.

“Berdiri kemudian berbaring sangatlah cepat tetapi tatkala sudah dituliskan akan menjadi kenangan yang taidak terlupakan sepanjang hayat”

Surakarta, Desember 2015 


\section{DAFTAR ISI \\ JURNAL PUSTAKA ILMIAH EDISI 1 VOLUME 1 TAHUN 2015}

Simbiosis Mutualisme Perpustakaan dengan Media Cetak sebagai Upaya Membudayakan Membaca dan Menulis bagi Masyrakat

Muhammad Rohmadi

Faktor Pengembangan dan Isu dalam Masalah Karier Pustakawan.

Masriyatun

Menguak Informasi via Alexa.com sebagai Evaluasi Menuju Optimalisasi Keberaksesan terhadap Perpustakaan dan Institusinya

Wiji Suwarno

Profesionalisme Pustakawan dalam Layanan Informasi

Sri Anawati

Public Space dan Private Space: Posisi Strategis Perpustakaan dalam Mendukung Pembelajaran Kolaboratif

Purwani Istiana

Mewujudkan World-class Professionalism of Librarians di Era Library Mobile

Yuni Nurjanah

Tantangan dan Kesiapan Pustakawan di Era Digital

Dian Hapsari

Formulasi Strategi Membangun Eksistensi Perpustakaan Perguruan Tinggi (Studi UPT Perpustakaan UNS Tahun 2015)

Riah Wiratningsih

Optimalisasi Perpustakaan Desa dalam Rangka Meningkatkan Pendidikan Masyarakat Bambang Hemanto

Optimalisasi Layanan Perpustakaan Perguruan Tinggi melalui Pemanfaatan Social Media Networking sebagai Media Komunikasi antara Perpustakaan dan Pemustaka Haryanto 


\title{
PUBLIC SPACE DAN PRIVATE SPACE : POSISI STRATEGIS PERPUSTAKAAN DALAM MENDUKUNG PEMBELAJARAN KOLABORATIF
}

\author{
Purwani Istiana \\ nina@ugm.ac.id / 08157936861
}

\begin{abstract}
The library has the resources in the form of a library room that can be optimized to provide support to collaborative learning. Library as a public space open for anyone to come, move, and enjoy the facilities of library. Library room with the support of information and communication technology-enabled to support collaborative learning process. Limitations of classrooms available on formal and informal education supported by information and communication technologies to make the library into a public space that is appropriate as the choice of implementation of the learning process. The availability of private space in a library makes the library has the advantage not only of space and collaborative learning facilities, but also a pleasant experience for pemustaka. The library is a public space, also the private sphere that gives comfort pemustaka for collaborative learning both online and offline. The space is flexible and responsive to the needs pemustaka become an important point in developing and optimizing the space available libraries.
\end{abstract}

Keywords: library, public space; private space, collaborative learning

\begin{abstract}
ABSTRAK
Perpustakaan memiliki sumber daya berupa ruang perpustakaan yang dapat dioptimalkan untuk memberi dukungan pada pembelajaran kolaboratif. Perpustakaan sebagai ruang publik terbuka bagi siapapun, untuk datang, beraktivitas, dan memanfaatkan berbagai fasilitas di dalamnya. Ruang perpustakaan dengan dukungan teknologi informasi dan komunikasi berkemampuan untuk mendukung proses pembelajaran kolaboratif. Keterbatasan ruang kelas yang tersedia pada pendidikan formal dan informal yang didukung oleh teknologi informasi dan komunikasi menjadikan perpustakaan menjadi ruang publik yang tepat sebagai pilihan pelaksanaan proses pembelajaran. Ketersediaan ruang privat di perpustakaan menjadikan perpustakaan memiliki keunggulan tidak hanya ruang dan fasilitas pembelajaran kolaboratif, tetapi juga pengalaman yang menyenangkan bagi pemustaka. Perpustakaan merupakan ruang publik sekaligus ruang privat yang memberi kenyamanan pemustaka untuk belajar secara kolaboratif, baik online maupun offline. Ruang yang fleksibel dan responsif bagi kebutuhan pemustaka menjadi poin penting dalam mengembangkan dan mengoptimalkan ruang perpustakaan yang tersedia.
\end{abstract}

Kata kunci: perpustakaan, public space, private space, pembelajaran kolaboratif 


\section{PENDAHULUAN}

Semua negara di dunia ini mengakui dan menjunjung tinggi ilmu pengetahuan sehingga pendidikan merupakan aspek yang mendasar bagi pembangunan kehidupan bangsa suatu negara. Definisi ilmu pengetahuan menurut KBBI (2008: 525) adalah gabungan berbagai pengetahuan yang disusun secara logis dan bersistem, dengan memperhitungkan sebab dan akibat. Ilmu pengetahuan bersifat rasional, empiris, dan sementara. Sifat sementara ilmu pengetahuan inilah yang menyebabkan ilmu pengetahuan terus dikembangkan dengan penyelidikan yang terus-menerus dilakukan. Pembahasan tentang pengembangan ilmu pengetahuan tidak pernahlepas dari pembicaraan tentang pendidikan. Pendidikan adalah usaha sadar dan terencana untuk mewujudkan suasana belajar dan proses pembelajaran agar peserta didik secara aktif mengembangkan potensi diri untuk memiliki kekuatan spiritual keagamaan, pengendalian diri, kepribadian, kecerdasan, akhlak mulia, serta keterampilan yang diperlukan dirinya, masyarakat, bangsa, dan negara (UU RI nomor 20 tahun 2003).

Semua orang menyadari pentingnya pendidikan. Pendidikan selalu berhubungan dengan sumber ilmu pengetahuan, sumber referensi, dan ruang belajar yang nyaman. Sumber ilmu pengetahuan dapat diperoleh melalui seseorang atau sekelompok orang yang kompeten di bidang tersebut melalui berbagai sumber referensi (buku, jurnal, dan sebagainya). Untuk memberikan pemahaman yang komprehensif tentang ilmu pengetahuan tertentu, kita belajar melalui pendidikan formal maupun informal. Pendidikan formal maupun informal, keduanya memerlukan dukungan ruang pembelajaran dengan berbagai sumber referensi pembelajaran yang nyaman. Kita tahu bahwa tidak semua pendidikan formal, bahkan informal mampu menyediakan ruang kelas yang memadai.
Saat ini, pembelajaran dalam pendidikan formal dan informal diarahkan pada metode pembelajaran kolaboratif. Tentunya untuk mendukung pembelajaran kolaboratif, diperlukan ruang pembelajaran kolaboratif. Ruanginimemilikikemampuanuntukkonfigurasi ulang tempat duduk dan mengakomodasi berbagai metode pembelajaran. Yang dapat kita garis bawahi dari ruang kolaboratif adalah kemampuan untuk konfigurasi ulang.

Semuajenis pendidikan, baikformalmaupun informal membutuhkan sumber referensi yang memadai dan tempat belajar yang nyaman. Sumber ilmu pengetahuan dapat diperoleh melalui berbagai sumber referensi. Untuk memberikan pemahaman yang komprehensif tentang ilmu pengetahuan tertentu, kita belajar melalui pendidikan formal maupun informal. Kedua jenis pendidikan tersebut memerlukan keberadaan perpustakaan sebagai sebuah tempat atau ruang untuk menggali dan mendalami suatu hal yang dipelajari. Mempelajari dan memdalami suatu hal dapat dilakukan dengan berbagai cara, misalnya diskusi dengan teman, belajar kelompok, belajar mandiri, dan sebagainya. Metode belajar semacam ini dapat dilakukan berdua, bertiga, atau kelompok yang lebih besar lagi.

Pendidikan dengan penekanan pada metode pembelajaran kolaboratif terkait dengan dukungan perpustakaan sebagai sumber belajar dan ruang belajar masyarakat menjadi menarik. Di sisi lain, perpustakaan sebagai ruang publik dituntut menyediakan sumber belajar dan ruang belajar bagi semua kelompok masyarakat sekaligus menyediakan ruang privat bagi penggunanya.

Tujuan penulisan artikel ini adalah menyampaikan informasi bahwa perpustakaan memiliki sumber daya ruang yang dapat dimanfaatkan seoptimal mungkin sehingga perpustakaan dapat lebih berkembang. Sebagaimana kita ketahui, sumber daya perpustakaan untuk mendukung terlaksananya 
pelayanan perpustakaan adalah pustakawan, koleksi, sarana dan prasarana, serta pemustaka (Istiana, 2014). Ruang perpustakaan merupakan sumber daya perpustakaan termasuk kelompok sarana. Sumber daya ruang perpustakaan sangat strategis bagi perpustakaan untuk memberikan dukungan pada pembelajaran kolaboratif. Peran perpustakaan sebagai penyedia ruang (space) yang nyaman, dengan berbagai fasilitas yang diperlukan, seperti akses internet, layar LCD, printer, dan scanner akan memberikan kontribusi bagi masyarakat pengguna untuk menciptakan iklim pembelajaran keberlanjutan dalam melakukan proses belajar sepanjang hayat.

\section{PEMBAHASAN}

\section{Perpustakaan sebagai Public Space dan Private space}

Perpustakaan selalu tumbuh, baik dalam pengertian tumbuh secara fisik, di mana ruang bertambah luas, maupun tumbuh dalam hal berbagaiaktivitaslayanan perpustakaansehingga bervariasi pula kebutuhan dan kepentingan pengguna yang datang ke perpustakaan. Sebagai public space, perpustakaan melayani masyarakat. Ruang publik akan terus menyesuaikan dengan kebutuhan masyarakat yang dilayani. Jika perpustakaan merupakan milik lembaga pendidikan tinggi, maka masyarakat yang dilayani adalah seluruh civitas akademika walaupun tidak tertutup bagi masyarakat luar. Perpustakaan merupakan tempat yang netral di mana siapapun/civitas akademika dapat datang ke perpustakaan, bertemu, dan saling berinteraksi. Disebutkan oleh May (2007) bahwa di ruang publik, anggota masyarakat merasa dapat diterima dan bersosialisasi dengan nyaman. Perpustakaan akan terus berkembang sesuai dengan kebutuhan pemustakanya. Sebagai pustakawan di lingkungan perpustakaan perguruan tinggi, penulis sangat memahami pertumbuhan perpustakaan perguruan tinggi, baik tumbuh secara fisik (gedung, ruang), berkembangan layanan, berbagai content yang disediakan, dan juga perluasan aktivitas pemustaka.

Perpustakaan perguruan tinggi sebagai public space bagi seluruh civitas akademika telah memberikan berbagai kontribusi. Daftar aktivitas pemustaka di perpustakaan dapat kita sebutkan, antara lain:

1. Membaca buku sendirian atau belajar mandiri.

2. Diskusi dua atau lebih teman.

3. Sekadar bertemu dan mengobrol dengan teman.

4. Mengetik dengan laptop untuk mengerjakan tugas.

5. Mengakses internet dalam rangka tugas ataupun hiburan.

6. Mengakses koleksi digital.

7. Melakukan aktivitas peminjaman dan atau pengembalian buku.

8. Melakukan penelusuran melalui sarana OPAC yang ada di perpustakaan.

9. Menghadiri pertemuan/pelatihan/ workshop.

10. Sekadar janji bertemu dengan teman di perpustakaan.

11. Melihat pameran, dan sebagainya.

Semua aktivitas tersebut di atas mengambil bagian di perpustakaan atau dilakukan di dalam perpustakaan. Aktivitas ini merupakan daftar aktivitas berdasarkan apa yang penulis lihat dan amati selama menjadi pustakawan.

Sebagai ruang publik, semua aktivitas yang dilakukan oleh pemustaka adalah baik dan bermanfaat. Perpustakaan menyediakan tempat yang sangat strategis untuk berbagai kegiatan. Perpustakaan merupakan tujuan utama bagi civitas akademika dalam beraktivitas. Kedekatan dengan sumber informasi dan pembelajaran menjadi pilihan utama bagi civitas akademika, terutama mahasiswa untuk berlama-lama di perpustakaan. Kata public yang melekat pada kata perpustakaan menjadikannya bersifat sangat terbuka bagi seluruh mahasiswa dari berbagai program studi di seluruh universitas 
untuk mengunjungi perpustakaan. Tidak ada kecanggungan bagi mereka untuk hadir di perpustakaan, berlama-lama, bahkan sampai jam kunjung perpustakaan berakhir.

Sebagai public space, perpustakaan sangat strategis dalam memberikan dukungan dalam pembelajaran kolaboratif. $\mathrm{Di}$ atas sudah disampaikan bahwa pemustaka sebuah perpustakaan perguruan tinggi berasal dari berbagai fakultas dan program studi yang ada di universitas tersebut, sifat terbuka ini sebagai posisi strategis perpustakaan untuk mendukung pembelajaran kolaboratif. Mahasiswa bebas melakukan pertemuan dan melaksanakan diskusi ilmiah atau sekadar mengobrol dengan teman-teman dari prodi lain, bahkan dari fakultas lain. Fasilitas ruang belajar tersedia dan memungkinkan mereka belajar bersama di perpustakaan. Semua prodi/fakultas dari semua strata, baik program diploma/vokasi, sarjana, dan pascasarjana dapat memanfaatkan perpustakaan universitas.

Selain bersifat terbuka, perpustakaan juga memiliki sifat privat. Hal ini diwujudkan dengan tersedianya fasilitas ruang-ruang privat untuk para pemustaka. Ruang ini disediakan untuk memenuhi kebutuhan privat satu atau beberapa orang. Setiap aktivitas pemustaka memiliki kebutuhan privasi yang berbedabeda. Tentu saja aktivitas yang ditekankan perpustakaan adalah aktivitas yang terkait dengan pembelajaran. Belajar mandiri untuk lebih fokus, perpustakaan menyediakan mejameja karel yang disediakan untuk pemustaka yang perlu melakukan aktivitas belajar sendiri. Belajar kelompok dengan 2 - 5 orang teman, perpustakaan menyediakan satu meja dengan jumlah kursi 2 - 6 orang. Untuk diskusi lebih banyak orang, perpustakaan juga menyediakan ruang dengan kapasitas lebih banyak lagi. Dengan demikian, walaupun perpustakaan adalah ruang publik, pemustaka dapat merasakan suasana privat dan khusus. Aktivitas yang dilakukan bersama atau berkelompok di perpustakaan juga merupakan aktivitas privat bagi kelompok tersebut. Perpustakaan menyediakan ruang yang dirancang sedemikian rupa sehingga memenuhi kebutuhan privat pemustaka, baik sendiri maupun berkelompok.

Pembelajaran yang memerlukan konfigurasi letak meja atau kursi dapat dilakukan di perpustakaan. Perpustakaan menyediakan ruang-ruang kecil, sedang, dan besar, yang memungkinkan mahasiswa dapat melaksanakan pembelajaran kolaboratif. Dukungan perpustakaan untuk pembelajaran kolabaratif tidak terjadi di perpustakaan tradisional (Gabbard, dkk., 2007), artinya perpustakaan tradisional tidak mengikuti pertumbuhan dan perkembangan masyarakat yang dilayani. Kita ketahui bahwa perpustakaan merupakan organisasi yang harus terus tumbuh dan berkembang sesuai kebutuhan masyarakatnya. Dalam hal ini, perpustakaan perlu mengoptimalkan sumber daya yang dimiliki, di antaranya ruang perpustakaan agar mampu menciptakan suasana pembelajaran kolaboratif.

\section{Pembelajaran Kolaboratif}

Pembelajaran kolaboratif berpandangan bahwa proses pembelajaran bersifat sosial. Dengan demikian, setiap individu yang terlibat dalam pembelajaran kolaboratif mengemukakan ide, pengalaman, mengambil peran asimetris, dan saling mengevaluasi ide dan pengalaman peserta lain sehingga ada interaksi satu dengan yang lain. Kegiatan belajar kolaboratif memiliki tujuan bersama dan setiap individu bertanggung jawab satu dengan yang lainnya sehingga saling tergantung untuk menyelesaikan tugas atau tujuan bersama. Sebagai contoh, kegiatan pembelajaran kolaboratif adalah menyelesaikan satu bentuk tulisan bersama atau pemecahan masalah lain. Setiap individu melakukan tugas yang berbeda, namun tetap saling melakukan koreksi atau evaluasi atas apa yang dikerjakan rekan yang lain. Dalam hal ini, peserta pembelajaran kolaboratif dapat menyampaikan 
ide dan pengalamannya untuk memberikan kontribusi dari tugas yang akan mereka selesaikan bersama.

Dalam pembelajaran kolaboratif, guru, dosen atau ketua kelompok berfungsi sebagai manajer pembelajaran. Peserta yang aktif dengan saling berinteraksi satu dengan yang lain berbagi ide dan pengalaman dengan tetap menjaga suasana saling menghormati, menghargai, dan saling menerima kelebihan dan kekurangan masing-masing. Guru atau dosen dalam proses pembelajaran kolaboratif juga dapat berinteraksi secara bebas dengan seluruh yang terlibat dalam pembelajaran kolaboratif. Peserta yang terlibat dalam diskusi kelompok dan tukar pendapat dapat saling memberi inspirasi bagi anggota yang lain, baik ide pembelajaran, topik, maupun motivasi.

Pembelajaran kolaboratif dengan karakteristik yang penulis sebutkan di atas tentu saja memerlukan ruang atau tempat yang sangat fleksibel. Seperti kita ketahui bahwa saat ini belum banyak ruang kelas yang tersedia di perguruan tinggi, yang memungkinkan untuk digunakan sebagai ruang pembelajaran kolaboratif. Meja kursi yang disediakan terbuat dari bahan yang cukup berat sehingga tidak mudah untuk dipindah atau digeser, serta berbagai sarana pembelajaran yang belum mendukung pelaksanaan pembelajaran kolaboratif.

Keberadaan fasilitas teknologi informasi dan telekomunikasi (akses online) menjadi salah satu sarana pendukung pembelajaran kolaboratif. Diskusi untuk menyampaikan ide, gagasan dan pengalaman memungkinkan peserta pembelajaran kolaboratif menggunakan sumber informasi online. Kita ketahui bersama bahwa tidak semua ruang kelas di suatu universitas menyediakan sarana akses internet. Keberadaan sumber daya listrik untuk mendukung seluruh peserta pembelajaran kolaboratif mendapatkan fasilitas ini juga belum terpenuhi di banyak kelas yang ada di perguruan tinggi.
Sebagai ruang publik, perpustakaan dituntut untuk mampu menciptakan ruang yang fleksibel dan responsif terhadap perubahan kebutuhan pemustaka. Ruang publik perpustakaan diharapkan didesain agar dapat memberikan kesan dan menyampaikan pesan (bermakna) bagi pemustaka sehingga mampu menginspirasi sebuah konsep proses pembelajaran yang nyaman dan menyenangkan. Kita barangkali harus sepakat bahwa desain ruang perpustakaan akan berpengaruh pada perilaku belajar. Berikut ini penjelasan perpustakaan sebagai ruang publik dituntut mampu menyediakan berbagai kebutuhan dan tanggap terhadap perubahan kebutuhan pemustaka.

\section{Fleksibel dan Responsif terhadap Perubahan Kebutuhan Pemustaka}

Pembelajaran kolaboratif membutuhkan ruang perpustakaan yang fleksibel untuk diatur ulang sesuai kebutuhan pemustaka. Perabotan yang disediakan mudah dipindah-pindah dan diatur untuk memenuhi model pembelajaran kolaboratif. Instruktur, guru, atau dosen dapat dengan mudah berpindah posisi untuk dapat menjangkau peserta didik. Meja dan kursi memungkinkan untuk dipindah atau digeser sesuai kebutuhan pembagian kelompok yang dikehendaki. Papan tulis (whiteboard) juga memungkinkan digeser atau dipindah, demikian pula layar LCD yang tersedia. Selain itu, sumber daya listrik memenuhi semua kebutuhan peserta didik. Ketersediaan akses internet yang memadai untuk menjangkau berbagai sumber pembelajaran online yang diperlukan. Dengan demikian, kata fleksibel dan responsif menjadi kata kunci bagi perpustakaan dalam penyediaan ruang pembelajaran kolaboratif. Kerja sama dengan pustakawan diperlukan dalam proses pembelajaran kolaboratif yang diselenggarakan di perpustakaan.

Pendekatan ruang perpustakaan yang fleksibel dan responsif terhadap kebutuhan ruang pembelajaran kolaboratif akan menciptakan satu kesan dan pengalaman mendalam yang 
menyenangkan bagi mahasiswa sehingga mampu menginspirasi pemustaka, dalam hal ini mahasiswa, dalam aktivitas belajar sepanjang hayat. Ruang-ruang privat dapat diciptakan atau didesain lebih menarik (Chandra \& Basuki, 2013). Pengalaman belajar yang mengasyikkan dan tidak membosankan, akan menjadi pengalaman yang terus dibawa sepanjang hidupnya. Walau mereka berada di ruang publik dengan sifat yang terbuka bagi siapapun, perpustakaan mampu menciptakan ruang fisik yang privat dan nyaman bagi pemustaka.

Perpustakaan adalah ruang publik yang mampu menghadirkan teknologi baru dan menggabungkannya dengan sumbersumber pembelajaran tradisional. Ruang publik yang dapat dimanfaatkan sebagai ruang privat ada di perpustakaan sehingga perpustakaan akan memberikan pengalaman belajar yang menyenangkan bagi pemustaka. Keberadaan perpustakaan dengan fasilitas belajar dan teknologi informasi yang memadai memungkinkan mahasiswa berhasil dalam lingkungan fisik dan digital. Lingkungan fisik, dalam hal ini perpustakaan mampu menyediakan ruang yang nyaman, terbuka namun privat. Lingkungan digital di mana perpustakaan mampu menyediakan akses dalam format digital melalui fasilitas teknologi informasi yang disediakan. Komunitas intelektual, baik secara offline maupun online dapat tercipta di perpustakaan. Kerja kelompok, belajar bersama, diskusi online maupun offline dapat dilakukan di perpustakaan. Sebagai contoh, mengerjakan tugas bersama, barangkali secara fisik hadir di perpustakaan hanya sendiri, namun melakukan aktivitas online bertiga dengan teman-teman menggunaan online tool/software (akses online) yang disediakan perpustakaan.

Dukungan teknologi informasi dan komunikasi di perpustakaan menjadi sangat berarti bagi pemustaka. Pengalaman berada di perpustakaan dengan aktivitas berkolaborasi secara online dengan pembelajar lain dan menyelesaikan satu tugas dalam proses pembelajaran menjadi pengalaman yang menyenangkan. Jika hal ini terus-menerus dilakukan, maka akan membentuk satu komunitas intelektual, di mana perpustakaan sebagai ruang publik secara tidak langsung berkontribusi dalam pembentukan komunitas intelektual. Komunitas intelektual merupakan sekelompok orang yang memiliki minat terhadap ilmu pengetahuan, yang berinteraksi untuk pengembangan ilmu pengetahuan.

\section{PENUTUP}

Ruang publik perpustakaan diharapkan didesain agar dapat memberikan kesan dan menyampaikan pesan (bermakna) bagi pemustaka sebagai tempat yang menarik, nyaman, dan memberikan pengalaman yang menyenangkan. Kita barangkali harus sepakat bahwa desain ruang perpustakaan akan berpengaruh pada perilaku belajar. Ruang perpustakaan diharapkan terus dikembangkan sesuai kebutuhan pemustaka. Dengan demikian, ruang yang diciptakan benarbenar ruang yang fleksibel dan responsif, yang mendukung pembelajaran kolaboratif. Pembelajaran kolaboratif dengan dukungan teknologi informasi dan komunikasi dilengkapi dengan sumber pembelajaran yang disediakan oleh perpustakaan akan sangat mendukung terbangunnya komunitas intelektual.

Ruang privat memberikan kenyamanan bagi pemustaka, baik mandiri maupun kelompok untuk melakukan aktivitas belajar yang menyenangkan. Pengalaman yang menyenangkan dan kenyamanan belajar di perpustakaanakanberdampakpadakeberlanjutan untuk memanfaatkan perpustakaan sebagai tempat yang nyaman. Dengan demikian, bukan sesuatu yang berlebihan ketika penulis menyampaikan judul tulisan ini bahwa ruang yang ada di perpustakaan yang bersifat publik dan privat merupakan posisi strategis bagi pelaksanaan pembelajaran kolaboratif. Kelengkapan dan kedekatan dengan sumber 
referensi pembelajaran dan dukungan teknologi lebih bagi perpustakaan yang tidak dijumpai informasi dan komunikasi seolah menjadi nilai pada ruang kelas pada umumnya.

\section{DAFTAR PUSTAKA}

Chandra, H., Kusumarini, Y., \& Basuki, L.. 2013. "Perancangan Small Private Space pada Interior Public Space di Perpustakaan Universitas Kristen Petra Surabaya”. Jurnal Intra, hlm.1 - 8.

Gabbard, R. B., Kaiser, A., \& Kaunelis, D.. 2007. "Redesigning a Library Space for Collaborative Learning”. Computers in Libraries, 27(5), pp:6. Retrieved from http:// search.proquest. com/ docview/ 231146935 ?ac coun tid=13771.

Istiana, P.. 2014. Layanan Perpustakaan. Yogyakarta: Ombak.

May, F.. 2007. "Libraries as Public Space: Patterns of Use in Nova Scotia Public Libraries (Order No.MR26876)". Available from ProQuest Dissertations \& Theses Global. (304789392). Retrieved from http://search.proquest.com/docview/304789392?account id =13771

Tim Penyusun.. 2008. Kamus Besar Bahasa Indonesia. Jakarta: Gramedia Pustaka Utama.

Undang-Undang Republik Indonesia Nomor 20 Tahun 2003 tentang Sistem Pendidikan Nasional. 